TERRA. Revista de Desarrollo Local e-ISSN: 2386-9968

Número 7 (2020), 340-345

DOI 10.7203/terra.7.19319

IIDL - Instituto Interuniversitario de Desarrollo Local

\title{
Reseña. Dinámicas de Urbanización en ciudades medias interiores. ¿Hacia un urbanismo más urbano?
}

\section{Sergio Tomé Fernández}

Profesor Titular de Análisis Geográfico Regional (Universidad de Oviedo, España) stome@uniovi.es

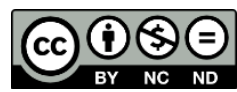

Esta obra se distribuye con la licencia Creative Commons Reconocimiento-NoComercial-SinObraDerivada 4.0 Internacional 


\section{SECCIÓN RESEÑAS}

\section{Reseña. Dinámicas de Urbanización en ciudades medias interiores. ¿Hacia un urbanismo más urbano?}

Resumen: La obra "Dinámicas de Urbanización en ciudades medias interiores" analiza la evolución de los núcleos de categoría intermedia situados fuera de las regiones litorales, en lo que va de siglo, tratando de darles sentido en el contexto de sus relaciones territoriales, y valora el efecto que han tenido en ellas los procesos de difusión espacial.

Palabras clave: Territorio, Geografía Urbana, Análisis Regional, Red Urbana, Ciudad Difusa.

Recibido: 18 de diciembre de 2020

Devuelto para revisión: -

Aceptado: 18 de diciembre de 2020

\section{Referencia / Citation:}

Tomé, S. (2020). Reseña. Dinámicas de Urbanización en ciudades medias interiores. ¿Hacia un urbanismo más urbano?. TERRA. Revista de Desarrollo Local, (7), 340-345. DOI 10.7203/terra.7.19319 


\title{
Francisco Cebrián Abellán (Coord.)
}

\section{DINÁMICAS DE URBANIZACIÓN EN CIUDADES MEDIAS INTERIORES. ¿HACIA UN URBANISMO MÁS URBANO?}

\author{
Valencia, Tiran Humanidades, 2020, 304 páginas
}

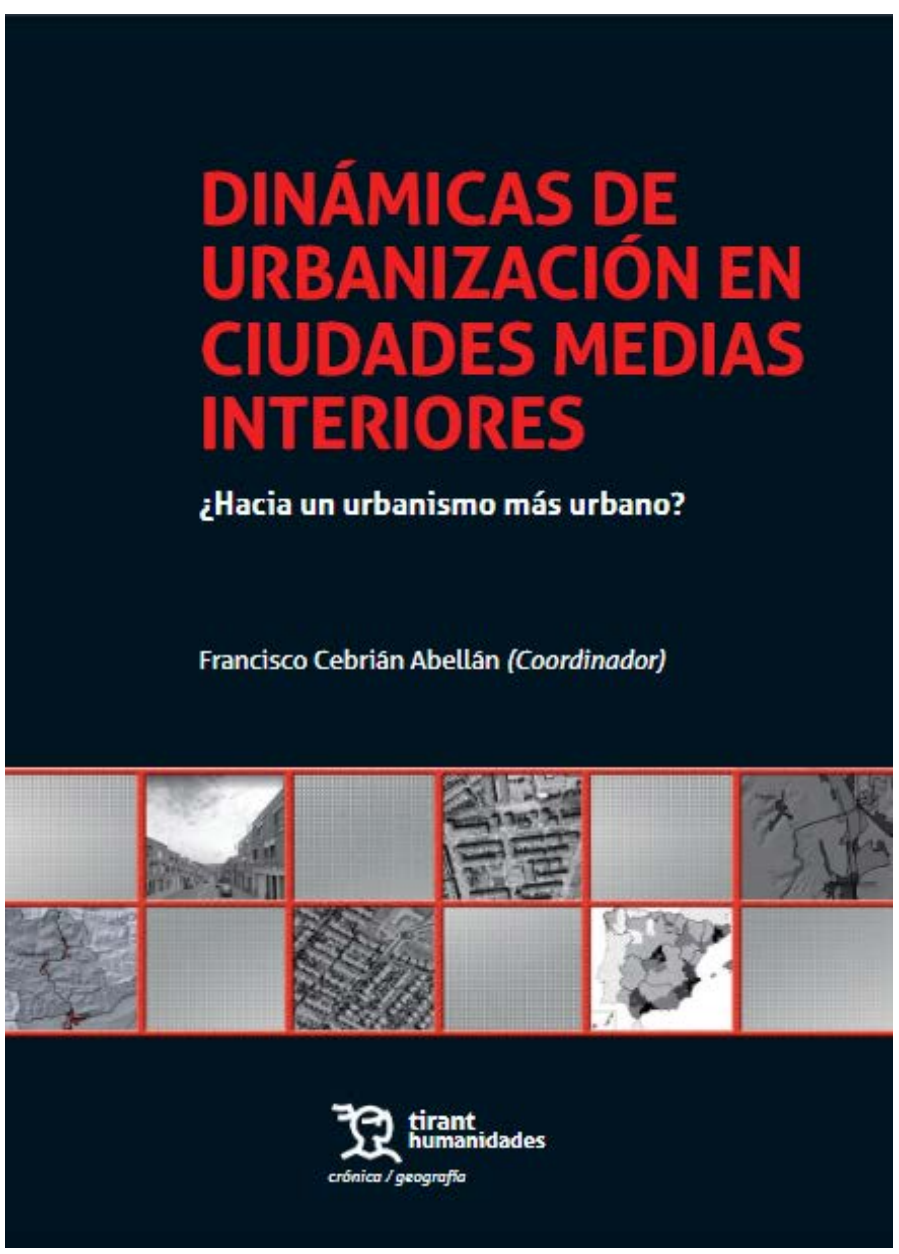

Puede hablarse de una obra coral, en la que quince geógrafos de seis Universidades presentan sus aportaciones al proyecto homónimo de I+D+I financiado por el Ministerio de Economía y Competitividad, más los resultados de otros proyectos previos. El coordinador, Francisco Cebrián Abellán, es un prestigioso especialista en estudios urbanos y regionales, que redacta el capítulo inicial y las conclusiones del libro, dándole coherencia, sentido y mayor valor añadido. Las bases de reflexión son la Dispersión Urbana y las Ciudades Medias, entendidas en sentido amplio (50.000-300.000 habitantes), durante el periodo 2000-2017 coincidente con la eclosión inmobiliaria, la crisis de 2008 y una incipiente recuperación muy localizada durante los últimos años. El texto soporta diversas lecturas pues parte de un encuadre general, utiliza diferentes perspectivas de acercamiento y juega con distintas escalas: el conjunto nacional, algunas regiones (Castilla La Mancha, Castilla y León, Madrid) y un total de once ciudades pertenecientes a las dos Castillas, Cantabria, Cataluña y Navarra, más las situadas en el área metropolitana de la capital, objeto todas ellas de análisis comparativos entrecruzados.

En la parte inicial y a la entrada de algunos capítulos posteriores se presenta, de forma fraccionada y con distintos puntos de vista, el estado de la cuestión acerca de la ciudad difusa y los procesos de exurbanización post fordistas, consecuentes con la metropolización. Es una síntesis meritoria, que recoge gran parte del enorme caudal de contribuciones pluridisciplinares existentes, entre otras las de los geógrafos, y aporta reflexiones propias acerca de las dimensiones espaciales, funcionales, políticas, ambientales y sociales. Con ellas queda bien patente la importancia de la Geografía en la discusión relativa a los modelos de crecimiento. La obra también proporciona una puesta al día sobre el concepto de ciudades medias o intermedias, valora la complejidad creciente de sus relaciones, bases de actividad y configuración material, al extenderse hacia municipios circunstantes, en contraposición con el declive de los entornos rurales más alejados y los pequeños núcleos. Recoge el principio fundamental de que esas 
poblaciones de rango mediano, debidamente reforzadas y conectadas, encierran un enorme potencial para articular el territorio de forma más armónica y eficiente; también resultan idóneas para experimentar estrategias de desarrollo urbano sostenible a escalas de intervención manejables.

El libro, de edición cuidada como es norma en el grupo valenciano Tirant, está organizado de manera que avanza desde lo general a lo particular. Los tres primeros capítulos contienen reflexiones amplias sobre las dinámicas y problemáticas concernientes el territorio, la composición regional, el rol de las ciudades medias en las redes urbanas y los procesos de desconcentración física, con especial referencia a España. Los capítulos restantes (del cuatro al ocho) extienden como ya se dijo el análisis espacio temporal a ciertas regiones interiores y sus ciudades, incluyendo igualmente algunas periféricas para buscar contraste (Figura 1). El denominador común a la totalidad es la utilización, en su parte empírica, de unas mismas variables de análisis: demográficas (crecimiento, migración, cambios de residencia), edificatorias y de incremento en la superficie ocupada según las imágenes de satélite. El cuerpo principal de la obra mide el considerable efecto del boom de la construcción en esas ciudades medias, mediante el cual llegó a ellas o se consolidó el modelo de la difusión urbana, proyectado sobre las coronas que rodean a los núcleos centrales.

Figura 1. Índice de capítulos/contenidos

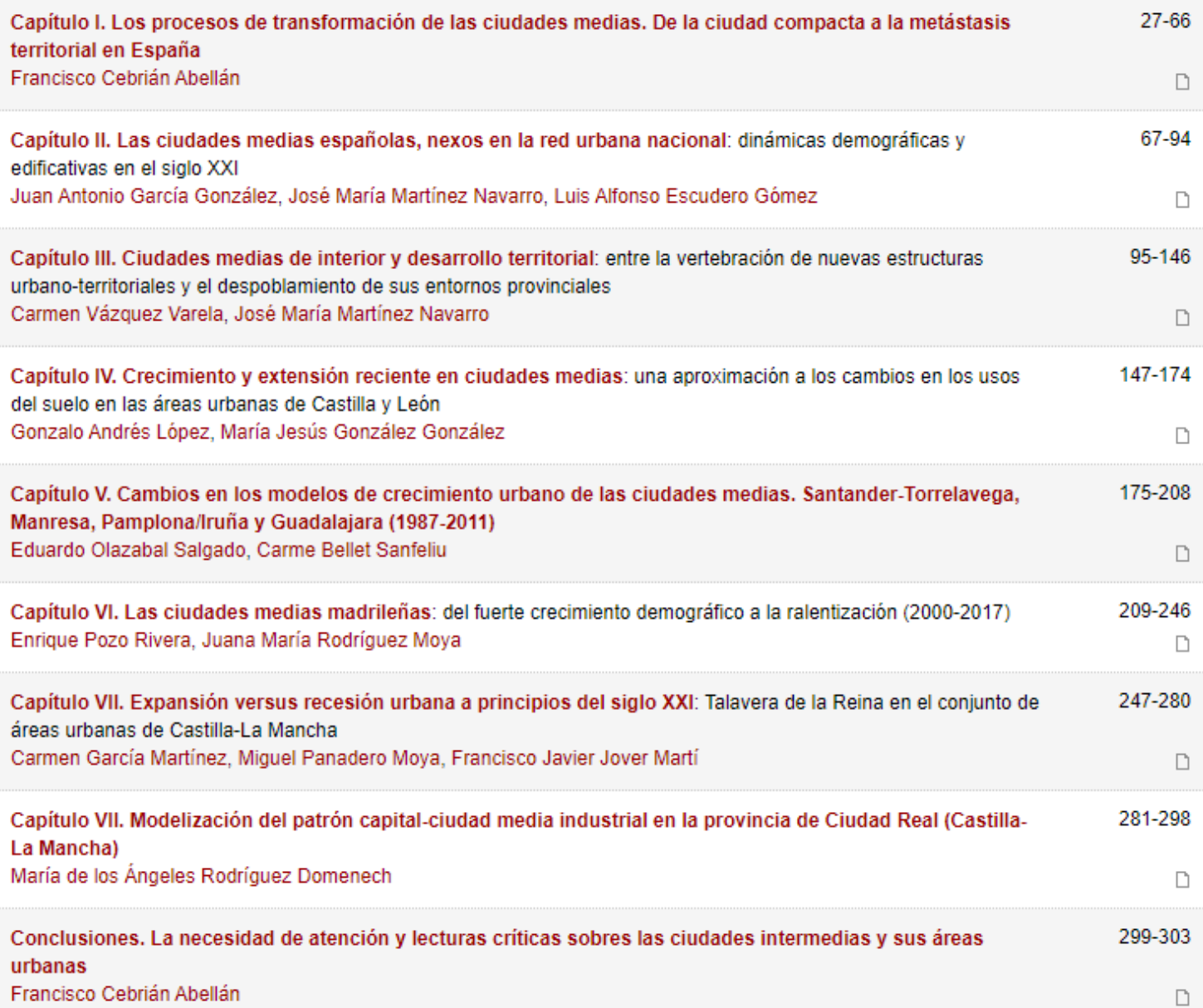


Las investigaciones realizadas por el colectivo firmante ponen de manifiesto que dentro del grupo estudiado hay trayectorias bien diferentes, dado que la intensidad de la dispersión, su envergadura y la manera de producirse varían, en función de una serie compleja de factores locales y otros propios del contexto regional. Los estudios de caso también revelan que el patrón de expansión o su magnitud relativa pueden resultar disímiles según categorías de núcleos. Por razones obvias, el mayor dinamismo suele registrarse en las ciudades medias orbitales de las áreas metropolitanas, particularmente Madrid, o insertas en zonas turísticas costeras. Pero la eclosión ha sido prácticamente universal, alcanzando incluso localidades con escasa o nula vitalidad demográfica, donde el sobrepeso de la construcción contrarresta la exigüidad o ausencia de otras actividades económicas con mayor valor añadido. Las consecuencias del Sprawl también son ambivalentes: han diseminado residentes, actividades y empleos de forma que a priori resulta beneficiosa, pero por regla general suponen el añadido de unas periferias hipertrofiadas, discontinuas, ocupadas con baja densidad pero también en forma compacta o localmente muy densa. El habitual fraccionamiento entre municipios con planes generales descoordinados, y la ocupación espontánea guiada por las vías de comunicación, dejaron a menudo composiciones incoherentes o disfuncionales.

La afección de dichos cambios al núcleo central entraña siempre reajustes de cierto alcance, y procesos de abandono o vaciamiento más vigorosos cuanto más pequeña sea la ciudad. En cuanto a la naturaleza de los usos que se descargan, la casuística es muy diversa, desde expansiones fundamentalmente residenciales, incluso de vivienda secundaria, hasta composiciones mixtas con funciones productivas, logísticas y grandes equipamientos. La edificación masiva de viviendas suele estar orientada por mecanismos de segregación socio espacial, que dan lugar a una ciudad dual, donde las movilidades internas cobran gran intensidad a pesar del tamaño poblacional reducido. Los paisajes resultantes son a su vez heterogéneos, pueden aportar un urbanismo de gran calidad formal y con buenas dotaciones, aunque lesivo para el entorno por el consumo extra que supone la extensividad, en los asentamientos exclusivos y de clase media; o al contrario, pueden adquirir una materialidad más improvisada, empobrecedora y con fuerte impacto al multiplicarse las construcciones seriadas y las naves, en tensión con la base rural.

Al bajar la marea desde 2008 las Administraciones se han visto obligadas a gestionar esas herencias, restañar heridas, recomponer espacios complejos necesitados de una ordenación del territorio supra municipal, y buscar respuesta para los polígonos y urbanizaciones a medio desarrollar. Las viviendas nuevas desocupadas, en un contexto de recrudecimiento del problema habitacional; la debilidad del transporte público, incongruente con el avance del cambio climático, son sólo algunos de los asuntos que obligan a revisar en profundidad el modelo urbano y el papel del Estado. Pero hay otra cuestión de fondo no menos trascendente, a la que el libro se acerca quizá de forma más tangencial o implícita. El desigual alcance local de la desconcentración urbana también debe interpretarse como resultado de una creciente asimetría entre ciudades, incluso dentro del intervalo medio. La jerarquía entre las que progresan (o tienen perspectivas al respecto), y las que decaen, por ejemplo en el noroeste y otras zonas interiores, implica en estas últimas el agravamiento de los problemas (envejecimiento, falta de empleo, descapitalización, deslocalizaciones, aislamiento) y una muy inferior posibilidad de afrontar con éxito la reorganización de las periferias y el desarrollo urbano.

Amén de lo ya señalado, entre las cualidades del texto no es cosa menor el establecimiento de relaciones dialécticas e interacciones entre las regiones, el mundo rural, las ciudades de distinto rango y las aglomeraciones. Se reconoce el desfase entre territorios y entre escalones de la red urbana, y la necesidad de un mejor conocimiento del eslabón 
representado por las ciudades medias, imprescindible para atender sus necesidades, y resolver los defectos de una expansión desmedida. Sobre este particular el libro fija la responsabilidad de la Administración, por dejación o favorecimiento, y aporta claves fundamentales que ayudan a comprender el declive de un buen número de poblaciones. Pone énfasis en los aspectos ecológicos, y plantea dudas sobre las lecciones extraídas de la crisis, a la vista de la reaparición de impulsos expansionistas, sin estrategias alternativas. Además de todo ello, el lector queda advertido acerca de la importancia capital del factor "situación geográfica", a la hora de explicar las dinámicas de opuestos en el mundo actual.

Al parecer de quien esto escribe, el único aspecto discutible de la obra, reconocido expresamente en ella, es el manejo de unos umbrales de población que, siendo correctos y de utilización habitual, condicionan parcialmente los resultados de la investigación a causa de su amplitud. Efectivamente una ciudad cuyo censo apenas rebasa los 50.000 habitantes no tiene a todas luces la misma categoría que otra cercana a 300.000, por eso se propuso hace tiempo la división entre un rango medio alto y otro medio bajo. La distancia entre ellos, sumada a otros factores, implica hoy día profundas repercusiones de muy diverso orden. En diversos capítulos del libro se ha evitado una excesiva simplificación incorporando las pertinentes distinciones por tamaños, aunque quizá no resaltan suficientemente la inferioridad de condiciones y la comprometida situación de muchas poblaciones de rango medio bajo, salvo que formen parte de las aglomeraciones metropolitanas $\mathrm{u}$ otras circunstancias especiales. Bien es verdad que ese no era propiamente el objetivo del proyecto de investigación.

En otro orden de cosas y como reflexión final, cabe reconocer el acierto de las alternativas planteadas, por el coordinador del trabajo y otros autores, para rectificar los trastornos de la difusión urbana y fortalecer las ciudades medias, poniendo en valor su potencial económico, territorial y social. Pero las propuestas chocan en gran medida con unas condiciones objetivas, determinadas por la implacable lógica de acumulación del capital, y la fuerza centrípeta de Madrid. El resultado es uno de los países con mayores desequilibrios territoriales de toda Europa, sin medidas correctoras, entre las cuales sería perentoria la discriminación positiva de las ciudades medias. Hace falta pues profundizar el debate, con la inestimable ayuda de los datos y reflexiones de este libro de Geografía, cuyo utilidad e interés para la comunidad científica y la ciudadanía no se ve empañado por la dificultad de leer algunos mapas, excesivamente reducidos.

Sergio Tomé Fernández

Profesor Titular de Análisis Geográfico Regional

Universidad de Oviedo

\section{IIVIINUNESITAT}

Institut Interuniversitari de Desenvolupament Local

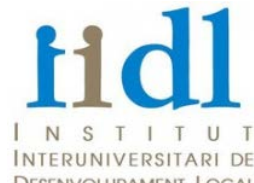

INTERUNIVERSITARI DE

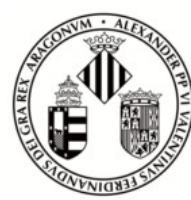

VNIVERSITAT (E) VAlÈnCia 